\title{
Measuring Vietnamese social work students' and non-social work students' attitudes toward poverty and poor population
}

\author{
Le Minh Tien ( $\nabla$ tien.Im@ou.edu.vn ) \\ Ho Chi Minh City Open University https://orcid.org/0000-0003-4659-6025
}

\section{Research Article}

Keywords: social work, poverty, attitudes, students, Vietnam

Posted Date: July 20th, 2021

DOI: https://doi.org/10.21203/rs.3.rs-734919/v1

License: (c) (i) This work is licensed under a Creative Commons Attribution 4.0 International License. Read Full License 


\section{Abstract}

The paper reports the results collected from social work students (SW) and non-social work students (NSW) of the Ho Chi Minh City Open University (OU), through attitudes toward poverty and poor people, in Vietnam. The Attitude toward Poverty Short Form (ATP-SF) 21-item (ATP-SF) scale, developed by Yun \& Weaver (2010), was used for the data collection. The sample of this study comprises 180 students enrolled at three disciplines such as social work $(n=86)$, law $(n=34)$, foreign language $(n=30)$ and economics $(n=30)$. The questionnaire was used to collect the data for the study. Cronbach alpha and independent t-test were run to compare means between two groups of students. All students were voluntarily participated in the survey.

Results: A total of 180 social work students and nonsocial work students at Ho Chi Minh City Open University in Vietnam were surveyed. Among them, 86 were social work students, the other 94 students were from law $(n=34)$, foreign language $(n=30)$ and economics $(n=30)$. The survey results showed that, when

looking for causes of poverty, social work students and nonsocial work students put most emphasis on structural factors of poverty. However, social work students, compared with nonsocial work students, consider personal deficiency and stigma more important.

\section{Introduction}

Through the past few decades, Vietnam has experienced fundamental economic, political, and social changes. On the one side, Vietnam has achieved significant improvements in poverty alleviation and social development. On the other hand, Vietnam is facing numerous new challenges due to rapid social change, including poverty, income inequality, family breakdown, rural-urban migration, unemployment, child labor, public health, and environmental pollution. In fact, the vast majority of Vietnam's remaining poor - 86 percent - are ethnic minorities (WB). In order to solve the social problems due to economic development, one of the solutions is development and professionalization of social work. In 2004, social work was officially recognized as a university discipline in Vietnam and the Ministry of Education and Training approved the national Bachelor of social work curriculum.

The social work profession has important roles in social development, intervening into lives of people, families, social groups, communities because the social work is a profession and not an ideology. According to the National Association of Social Workers Code of Ethics, social workers pursue social change, particularly with and on behalf of vulnerable and oppressed individuals and groups of people. Social workers' social change efforts are focused primarily on issues of poverty, unemployment, discrimination, and other forms of social injustice. Similarly, Clark (2007) noted that most students agreed that the traditional mission of social work emphasizes helping the poor and disadvantaged through direct services and advocacy in the form of political and social action. Therefore, poverty is one of the main interests in the field of social work, and future social workers are expected to show greater understanding for the poor. For this reason, it is important to identify how social work students perceive the causes of poverty.

To date, a lot of studies have been conducted to explore individual attitudes toward poverty and poor population. Schwartz and Robinson (1991), by using the Feagin Poverty Scale, investigated the perceptions of the causes of poverty of the three groups of social work students at a midsized urban university in the 
Midwest with a department of social work and found that all three groups attributed poverty mostly to the structural factor, and least to personal deficiency. Similarly, Rosenthal (1993) developed two scales (The Belief in Individual Cause of Poverty scale and The Antipathy to the Poor scale in measuring the attitudes of graduate social work students toward impoverished people. Rehner and colleagues (1997) used the Attitude toward Poverty developed by Atherton and his colleagues (1993) to study the Mississippi social workers' attitude toward poverty and the poor.

Another study, conducted by Sun (2001), the Feagin's Poverty scale was used to measure social work students' ans non-social work students' perceptions of the causes of poverty. In 2010, Yun \& Weaver developed the 21-item Attitude toward Poverty Short Form scale that measures people's attitudes toward poverty and poor people. This scale includes three factors which measure a range of diverse attitudes toward poverty and poor population such as the personal deficiency, the stigma and the structural perspective. Brief summaries of the previous studies on student perceptions of causes of poverty provide a context for the current study.

Therefore, the purpose of this study is to identify what social work students (SW) and non-social work (NSW) students perceive as the causes of poverty. Understanding the perceived causes of poverty is important in addressing the issue of poverty. To the knowledge of the author, this paper is probably the first to measure the students' attitudes toward poverty in Vietnam to date.

\section{Main Text}

\section{Objectives of the Study}

Based on the brief literature review of attitudes toward poverty research, the author determines the following research aim of this paper such as:

- - To test the 21-item of the ATP-SF developed by Yun \& Weaver (2010) in the Vietnamese context.

- - To explore the perceptions of Vietnamese students on the causes of poverty.

- - To examine the differences in perceptions and attitudes of poverty between students of social work, and nonsocial work.

\section{Materials And Methods}

\section{Data collection}

The data were collected in August 2020, the first semester of the academic year 2020-2021. Participants who are full-time second year and third year students at Ho Chi Minh City Open University, Ho Chi Minh City, Vietnam decided to take part in the survey voluntarily. The survey were conducted by using convenience nonprobability sampling and based on survey questionnaire.

The survey questionnaire includes two parts: the first section contains items collecting information about the respondent's characteristics, including gender, university year of studying, age, academic performance, 
ethnicity, student's family economic status. The second part consists of 21 items related to attitudes of respondents about poverty and/or impoverished persons. The questionnaire items have been used from previous research, developed by Yun \& Weaver (2010) including three dimensions of poverty: the personal deficiency 7-item subscale measured "individualistic beliefs" that indicated a person feels that poverty is due to factors such as lack of ability or lack of effort; the stigma 8- item subscale measured if a person has stigma toward individuals living in poverty such as increased fraud, feelings of entitlement, and being lazy; and the structural perspective 6-item subscale measured one's willingness to support social programs and society's responsibility to help the poor. The items are scored on a 5 -point Likert scale such as $1=$ strongly agree, 2 = agree, 3 = neutral, 4 = disagree, 5 = strongly disagree. All the 21 items were summed to create a total score with a range between 21 and 105 . Higher scores denote strong negative attitudes toward three dimensions of poverty and lower scores reflect more positive attitudes toward three dimensions of poverty. Probably, this was the first application of the ATP-SF in the Vietnamese context.

However, as the participants are Vietnamese students, therefore, the items were translated into Vietnamese from the original English version. Some words have been modified to be more suitable to the Vietnamese context (For example: "federal budget" is replaced by "state budget"). After obtaining the lecturers' permission, the author administered questionnaires to students in their classrooms. Students were told that the study was to explore their perceptions of poverty, and were told that the study was voluntary and anonymous, respondents' names were not included in the data to maintain privacy. To complete the questionnaire form, students spent about $15 \mathrm{~min}$ answering all questions. The results collected 180 valuable responses.

\section{Data analysis}

The collected data was entered and analyzed using Excel and SPSS version 20 (SPSS, Inc., Chicago IL, US), respectively. Descriptive statistics such as frequencies and percentages were presented using tables. For reliability, internal consistency reliability of 21 items of the three constructs of poverty was carried out by calculating the Cronbach Alpha coefficient. In addition, we used the independent-samples $t$-test (one-tailed) test to compare means between SW students and NSW students. The level of significance was set at $(\mathrm{P}<$ 0.05).

\section{Results And Discussion}

The results of the survey are as follows

\section{Demographic characteristics}

A total of 180 students participated in the study. Among them, 86 were social work students, the other 94 students were from law $(n=34)$, foreign language $(n=30)$ and economics $(n=30)$. Gender distribution included 42 males $(23.3 \%)$ and 138 females $(76.7 \%)$. The majority of students that completed the survey were females because of the number of female students of the Ho Chi Minh City Open University is more than seventy percent. University year of studying distribution included 105 (58.3\%) second year students and 75 
$(41.7 \%)$ third year students. The mean age of the entire sample was 20.5 years old $(S D=0.95)$. The demographic characteristics of the participants are summarized in Table 1.

\section{Table 1. Demographic characteristics of the sample}


Variables

Category

Frequency Percent (\%)

Gender

Total

180

100.0

Male

42

23.3

Female

138

76.7

University year of

Total

180

100.0

studying

Second year

105

58.3

Third year

75

41.7

Fields of study

Total

180

100.0

Social work $\quad 86$

47.8

Non-social

94

52.2

work

Total

176

97.8

performance

Very good

17

9.4

Fair

112

62.2

Average

47

26.1

Missing 
Family economic status
Total

High income $\quad 60$

Middle

109

60.6

income

11

6.1

33.3

\section{Low income}

Total

Kinh

(vietnamese)

Others

Missing
178

98.9

173

96.1

5

2.8

1.1 
than 0.70 shows relatively high internal consistency. Thus, the three subscales of the questionnaire were satisfactory reliability. Specifically, the Cronbach's Alpha coefficient for Personal deficiency factor was 0.698, the Cronbach's Alpha coefficient for Stigma factor was 0.652 and the Cronbach's Alpha coefficient for Structural perspective factor was 0.586. Thus, compared to the Yun \& Weaver study (2010), the Cronbach's Alpha coefficients of this study were lower.

\section{Table - 2. Descriptive results of participants' responses}


Variables Statements

$\mathbf{N}$

Min Max Mean SD

Personal deficency (PD) (Cronbach's Alpha = 0.698)

PD1

Poor people are different

from the rest

of society
178* $1 \quad 5 \quad 3.74 \quad 0.90$

$\begin{array}{llll}180 & 2 & 5 & 4.38\end{array}$

0.73

PD2 $\quad \begin{aligned} & \text { Poor people } \\ & \text { are dishonest }\end{aligned}$

PD3

Most poor

$178 * 2$

5

$4.57 \quad 0.67$

people are

dirty

PD4

Poor people

$179 * * 1$

5

4.15

0.84 act differently

PD5

Children

$179 * * 3$

5

4.60

0.55

raised on

welfare will

never amount

to anything

PD6

I believe poor 179** 1

5

2.92

1.17

people have a

different set

of values than

do other

people 
$\begin{array}{lllllll}\text { PD7 } & \text { Poor people } & 180 & 2 & 5 & 4.34 & 0.78\end{array}$ generally have

lower

intelligence

than nonpoor

people

Stigma (STg) (Cronbach's Alpha = 0.652)

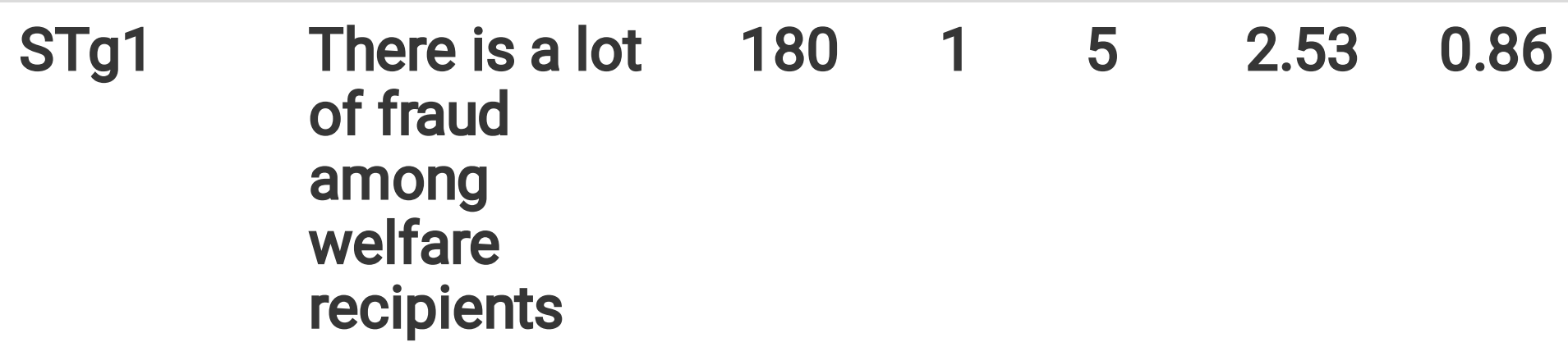

STg2

Some "poor"

180

$5 \quad 3.12$

$3.12 \quad 0.87$

people live

better than I

do,

considering all

their benefits

STg3

Poor people

180

1

think they

deserve to be

supported

STg4

Welfare

180

1

5

$3.26 \quad 1.03$

mothers have

babies to get

more money 
An able-

180

1

5

$3.07 \quad 1.08$

bodied person

collecting

welfare is

ripping off the

system

STg6

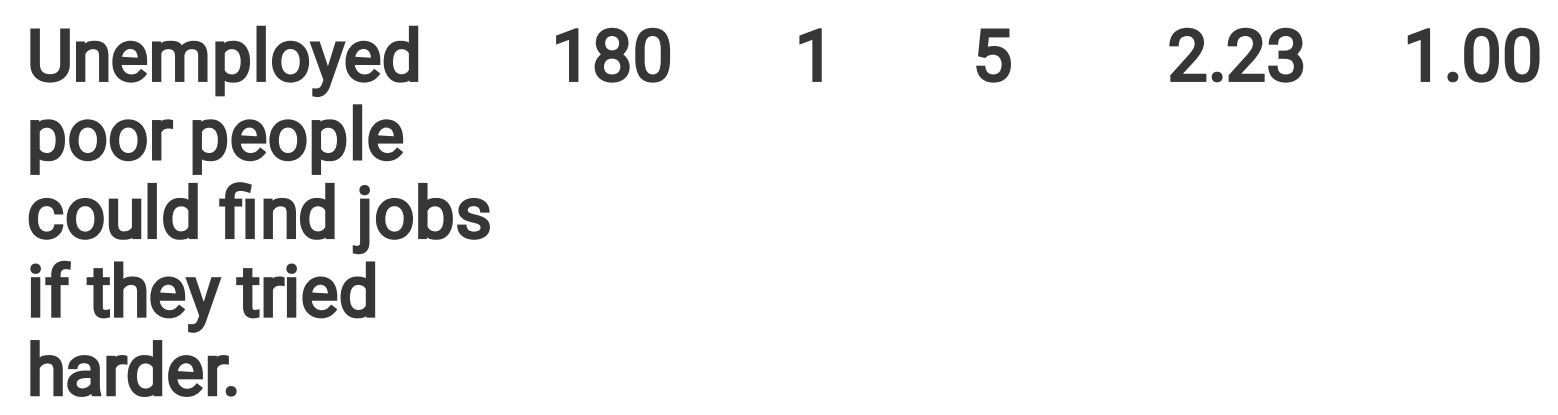

STg7

Welfare

180

$\begin{array}{lll}1 & 5 & 2.92\end{array}$

0.98

makes people

lazy

STg8

Benefits for

180

$\begin{array}{lll}1 & 5 & 3.03\end{array}$

0.77

poor people

consume a

major part of

the state

budget

Structural perspective (SP) (Cronbach's Alpha = 0.586)

$\begin{array}{lllllll}\text { SP1 } & \begin{array}{l}\text { People are } \\ \text { poor due to } \\ \text { circumstances }\end{array} & 179 * * & 1 & 5 & 2.71 & 1.07 \\ & & & & & \end{array}$




\section{beyond their control}

SP2

I would

180

$5 \quad 3.34$

0.99

support a

program that

resulted in

higher taxes to

support social

programs for

poor people

SP3

$\begin{array}{llllll}\text { If I were poor, I } & 180 & 1 & 5 & 2.54 & 0.88\end{array}$ would accept

welfare

benefits

SP4

People who

$179 * * 1$

5

1.92

0.87

are poor

should not be

blamed for

their

misfortune

Society has

180

1

5

$2.45 \quad 0.93$

the

responsibility

to help poor

people

$\begin{array}{llllll}\text { Poor people } & 180 & 1 & 5 & 2.31 & 0.89\end{array}$ 


\section{are \\ discriminated against}

\section{Note:}

\section{SD = Standard deviation}

\section{* Missing: 2 cases; ** Missing: 1 case}

A comparision of the mean scores for the attitudes toward poverty between SW students and NSW students are presented in Table 3. An independent-samples $t$-test using (one-tailed), the significant differences were found in the personal deficiency dimension and in the stigma dimension of poverty scores among the two groups of students.

\section{Table - 3. Independent-samples t-test between SW students and NSW students on three dimensions of poverty}




\section{Dimensions Group of $\mathrm{N}$ Mean $\mathrm{t}$ df Sig. students

\section{Personal \\ SW \\ $86 \quad 3.97$ \\ $-3.709$ \\ 178 \\ 0.000}

deficiency

\section{NSW $\quad 94 \quad 4.23$}

Stigma

SW

$86 \quad 2.71$

$-4.639178$

0.000

\section{NSW $\quad 94 \quad 3.04$}

\section{Structural \\ perspective}

SW

$86 \quad 2.52$

$-0.776178$

0.439

NSW $\quad 94 \quad 2.58$

\section{Note: SW = Social work; NSW = Non-social work}

As such, when looking for causes of poverty, SW students and NSW students put most emphasis on structural factors of poverty. However, SW students, compared with NSW students, consider personal deficiency and stigma more important. These findings are not consistent with similar studies conducted in other countries. For example, a study conducted by Ljubotina \& Ljubotina (2007) in Croatia indicated that SW students perceived individual factors as significantly less important causes of poverty than students of economics and agriculture. Another study conducted by Wollie (2009) also showed that youths in Bahir Dar (Ethiopia) were more inclined to attribute poverty to structural factors. The SW students were favoured more on the personal deficiency and the stigma in the poverty explanation because the social work teaching of the Ho Chi Minh City Open University focuses more on social work with individuals. Indeed, the aim of the Ho Chi Minh City Open University' social work education is "the project management, project work on community development, social development, participation in poverty reduction project, capacity building for women, career orientation and job creation for youth, participating in the construction of the saving credit programs"

\section{Conclusion And Limitations}


Indeed, Vietnamese social work is in its infancy (Nguyen \& Nguyen, 2016), this is an exploratory study in nature. The survey results indicated that SW students and NSW students put most emphasis on structural factors of poverty. However, NSW students did not overwhelmingly attribute poverty to personal and stigma factors as expected and this finding is consistent with previous study. Individualistic and stigma perspective are internal factors and indicate negative attitude toward poverty, thus the finding indicates SW students are more likely to incline to negative or internal attitude toward poverty. This is a main challenge for the professional socialization and the congruence with the desired social work values. Therefore, social work education must provide opportunities for SW students to compare their views of the social issues such as poverty.

The current study has several limitations. Firstly, the research was limited by a small sample size and the sample was limited to one university, so its limited possibility to generalize the findings to all other social work or nonsocial work students. Thus, future research could strengthen the findings of this study by exploring the attitudes toward poverty in other universities. Additionally, future research should investigate the attitude toward poverty among the poor individuals and the Vietnamese people too. This can provide a better understanding about the causal factor to poverty so that further improvement to the current social work education program can be done.

Finally, the data analysis used only descriptive statistics, thus, another future research direction is to explore the attitudes toward poverty by applying multivariate statistical methods such as logistic regression models and/or correspondence analysis. Research into the attitudes toward poverty could serve as a good guideline for the creators of social policies focused at preventing or helping eradicate poverty.

\section{Declarations}

\section{Acknowledgements}

The author sincerely thank students who participated in the survey as well as the lectures who supportes him during the process of collecting data. The author would like to acknowledge the Ho Chi Minh City Open University for the financial support of this work.

\section{Funding}

This research was funded by Ho Chi Minh City Open University, grant number T2019.10.1.

\section{Availability of data and materials}

The data are not available for public access because of privacy concerns, but are available from the corresponding author on reasonable request.

\section{Ethics approval and consent to participate}

All students agree to participate in research voluntarily

\section{Consent for publication}


Not applicable.

\section{Competing interests}

The author declares that there are no known competing financial interests or personal relationships that have or could be perceived to have influenced the work reported in this article.

\section{Author details}

Faculty of Sociology-Social Work-Southeast Asian Studies, Ho Chi Minh City Open University, Vietnam 35-37 Ho Hao Hon st, Ho Chi Minh City, Vietnam

\section{References}

\section{References}

1. Atherton, C. R., Gemmel, R. J., Haagenstad, S \& Holt, D. J. (1993). Measuring attitudes toward poverty: A new scale, Social Work Research \& Abstracts, 29, 28-30

2. Clark, S. (2007). Social Work Students' Perceptions of Poverty, Journal of Human Behavior in the Social Environment, Vol. 16 No. 1-2, 149-166. DOI: 10.1300/J137v16n01_10.

3. Ho Chi Minh City Open University. Introduction of programs. Available at: http://en.ou.edu.vn/pages/view/141/introduce-programs?focus=3.

4. Ljubotina, O.D., Ljubotina, D. (2007). Attributions of poverty among social work and non-social work students in Croatia, Croatian medical journal, Vol. 48 No. 5, 741-749.

5. National Association of Social Workers. Code of Ethics, Ethical Principles. Washington, DC: Author. Available at: https://www.socialworkers.org/LinkClick.aspx?fileticket=KZmmbz15evc\%3d\&portalid=0.

6. Nguyen, H., Nguyen, T.T. (2016). Optimistic but Confused: Perceptions about the Mission and Core Values of Social Work in Vietnam by Vietnamese Policy-makers, Social Work Faculty and Practitioners, Asian Soc Work Pol Rev. No. 11, 53-65, https://doi.org/10.1111/aswp.12113.

7. Rehner, T., Ishee, J., Salloum, M., Velasques, D. (1997). Mississippi social workers' attitudes toward poverty and the poor, Journal of Social Work Education, Vol. 33 No. 1, 131-142, https://doi.org/10.1080/10437797.1997.10778858.

8. Rosenthal, B.S. (1993). Graduate social work students' beliefs about poverty and attitudes toward the poor, Journal of Teaching in Social Work, Vol. 7 No. 1, 107-121, https://doi.org/10.1300/J067v07n01_09.

9. Schwartz, S., Robinson, M.M. (1991). “.Attitudes toward Poverty during Undergraduate Education, Journal of Social Work Education, Vol. 27 No. 3, 290-296, DOI: 10.1080/10437797.1991.10672201.

10. Sun, A. (2001). Perceptions among social work and non-social work students concerning causes of poverty, Journal of Social Work Education, Vol. 37 No. 1, 161-173, doi:10.1080/10437797.2001.10779044. 
11. Taber, K.S. (2018). The Use of Cronbach's Alpha When Developing and Reporting Research Instruments in Science Education, Res Sci Educ, Vol. 48, 1273-1296, https://doi.org/10.1007/s11165-016-9602-2.

12. The World Bank in Vietnam. Vietnam Overview. Available at: https://www.worldbank.org/en/country/vietnam/overview.

13. Wollie, C.W. (2009). Causal Attributions for Poverty among Youths in Bahir Dar, Amhara Region, Ethiopia, Journal of Social, Evolutionary and Cultural Psychology, Vol. 3 No. 3, pp. 251-272, http://dx.doi.org/10.1037/h0099319.

14. Yun S. H., Weaver, R.D. (2010). Development and validation of a short form of the Attitude Toward Poverty Scale, Adv Soc Work, Vol. 11 No. 2, 174-187, https://doi.org/10.18060/437.

\section{Supplementary Files}

This is a list of supplementary files associated with this preprint. Click to download.

- datapoverty.xls 